\title{
Simultaneous Determination of Flavonoids from Bamboo Leaf Extracts Using Liquid Chromatography-Tandem Mass Spectrometry
}

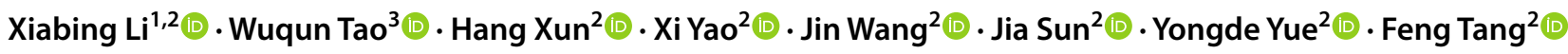

Received: 19 November 2020 / Accepted: 3 May 2021 / Published online: 29 June 2021

(c) The Author(s) 2021

\begin{abstract}
An analytical method for the simultaneous determination of ten major functional flavonoids (isoorientin, orientin, vitexin, isovitexin, apigenin, luteolin, tricin, quercetin, rutin, and kaempferol) in different bamboo species was developed by liquid chromatography-tandem mass spectrometry. Chromatographic separation was carried out on a reversed-phase C-18 column with acetonitrile and water as the mobile phases. Detection was performed in negative ion electrospray ionization mode using multiple reaction monitoring mode. The correlation coefficients for the calibration curves ranged from 0.9955 to 0.9997. The limit of detection ranged from 1 to $45 \mathrm{ng} / \mathrm{ml}$. The applicability of this analytical approach was confirmed by the successful analysis of real leaf samples of four bamboo species, family Poaceae: Pleioblastus amarus (Keng) Keng f., Phyllostachys glauca McClure, Phyllostachys edullis (Carrière) J.Houz, and Indocalamus latifolius (Keng) McClure. The total flavonoid contents were $3321.09,3095.96,4037.33$, and $2808.42 \mathrm{mg} / \mathrm{kg}$ for P. amarus, P. glauca, P. edullis, and I. latifolius, respectively.
\end{abstract}

Keywords Bamboo leaf flavonoids $\cdot$ LC-MS-MS $\cdot$ Multiple reaction monitoring $\cdot$ Different ethanol extracts

\section{Introduction}

Bamboo, an important building material and a potential source of bioactive substances, is widely distributed in the tropics and subtropics (Lu et al. 2005). Bamboo leaves have been used as food and folk medicine for more than 1000 years in China (Lu et al. 2005; Gong et al. 2015). Numerous studies have shown that the major bioactive components of bamboo leaf extract are flavonoids including kaempferol (1), rutin (2), orientin (4), isoorient (8), vitexin (9) and isovitexin (10), and quercetin (5) (Zhang et al. 2005; Lee et al. 2010; Wang et al. 2010; 2012; Wu et al. 2012; Ma

Feng Tang

fengtang@icbr.ac.cn

1 School of Chemistry and Life Sciences, Chuxiong Normal University, Chuxiong 675000, Yunnan, China

2 National Forestry and Grassland Administration Key Open Laboratory, International Centre for Bamboo and Rattan, Beijing 100102, China

3 State Key Laboratory of Environmental Chemistry and Ecotoxicology, Research Center for Eco-Environmental Sciences, Chinese Academy of Sciences, Beijing 100085, China et al. 2012; Mao et al. 2013). Previous studies have reported that flavonoid-rich bamboo leaf extracts have a variety of biological effects including antioxidant, anticancer, antibacterial, antiviral, anti-inflammatory, and antimutagenic effects (Lu et al. 2005; An et al. 2012; Van Hoyweghen et al. 2012). These extracts can also be used as ingredients in dietary supplements and food additives (Lu et al. 2005; Zhang et al. 2007; Koide et al. 2011; Gong et al. 2015), in part, due to the antioxidant activity of bamboo leaves. Antioxidants from bamboo leaves can be added to the puffed grain food (corn, rice, wheat, and amaranth, inter alia, for snacks and food product) meat products and oils, as authorized by the Ministry of Health, PR China (Lu et al. 2005). Bamboo leaf flavonoids are also important in fat resistance and effective in the treatment of cancer and aging (Hu et al. 2000).

Concerning the extensive utilization of bamboo leaf flavonoids in the functional food industry and commercial products, it is necessary to develop a method to quantitatively determine active flavonoids and ensure quality control of these extracts. Some analytical methods have been reported for the simultaneous quantitation of two or four flavonoid constituents, including $\mathbf{8}, \mathbf{1 0}, \mathbf{4}$, and 9 in bamboo leaf extracts. Analytical methods include thin-layer chromatography (TLC) (Wang et al. 2012), high-performance liquid chromatography HPLC (Zhang et al. 
2005), high-performance capillary electrophoresis (HPCE) (Lu et al. 2005), high-performance thin-layer chromatography (HPTLC) (Sun et al. 2010; Jian et al. 2011), and high-performance liquid chromatography-mass spectrometry (HPLC-MS) (Pereira et al. 2010). However, to date, liquid chromatographytandem mass spectrometry (LC-MS-MS) methods have not been developed for the simultaneous analysis of the ten major flavonoids in bamboo leaves. LC-MS-MS has been recognized as a powerful analytical tool for the fast measurement of various analytes, such as polar, nonvolatile, high molecular mass compounds in natural product research compared to reversedphase standalone HPLC coupled with diode array detection $(\mathrm{Zu}$ et al. 2006). In this study, a simple, sensitive, and throughout LC-MS-MS method was first developed and validated for the simultaneous determination of ten flavonoids: kaempferol (1), rutin (2), tricin (3), orientin (4), quercetin (5), luteolin (6), apigenin (7), isoorientin (8), vitexin (9), and isovitexin (10), which are generally considered to be the major constituent flavonoids of bamboo leaves (Yang et al. 2017), in a single run and to demonstrate the applicability of the method for the analysis of leaf samples from four species of bamboo.<smiles>[R]c1cc(-c2oc3c([R4])c(O)c([R3])c(O)c3c(=O)c2[R5])cc([R2])c1O</smiles>
$1 \mathrm{R}_{1}=\mathrm{R}_{2}=\mathrm{R}_{3}=\mathrm{R}_{4}=\mathrm{H} ; \mathrm{R}_{5}=\mathrm{OH}$
$2 \mathrm{R}_{2}=\mathrm{R}_{3}=\mathrm{R}_{4}=\mathrm{H} ; \mathrm{R}_{1}=\mathrm{OH} ; \mathrm{R}_{5}=\mathrm{OGlu}_{6}{ }^{-1} \mathrm{Rha}$
$3 \mathrm{R}_{1}=\mathrm{R}_{2}=\mathrm{OCH}_{3} ; \mathrm{R}_{3}=\mathrm{R}_{4}=\mathrm{R}_{5}=\mathrm{H}$
$4 \mathrm{R}_{2}=\mathrm{OH} ; \mathrm{R}_{1}=\mathrm{R}_{3}=\mathrm{R}_{5}=\mathrm{H} ; \mathrm{R}_{4}=\mathrm{Glu}$
$5 \mathrm{R}_{2}=\mathrm{R}_{5}=\mathrm{OH} ; \mathrm{R}_{1}=\mathrm{R}_{3}=\mathrm{R}_{4}=\mathrm{H}$
$6 \mathrm{R}_{1}=\mathrm{OH} ; \mathrm{R}_{2}=\mathrm{R}_{3}=\mathrm{R}_{4}=\mathrm{R}_{5}=\mathrm{H}$
$7 \mathrm{R}_{1}=\mathrm{R}_{2}=\mathrm{R}_{3}=\mathrm{R}_{4}=\mathrm{R}_{5}=\mathrm{H}$
$8 \mathrm{R}_{2}=\mathrm{OH} ; \mathrm{R}_{1}=\mathrm{R}_{4}=\mathrm{R}_{5}=\mathrm{H} ; \mathrm{R}_{3}=\mathrm{Glu}$
$9 \mathrm{R}_{1}=\mathrm{R}_{2}=\mathrm{R}_{3}=\mathrm{R}_{5}=\mathrm{H} ; \mathrm{R}_{4}=\mathrm{Glu}$
$10 \mathrm{R}_{1}=\mathrm{R}_{2}=\mathrm{R}_{4}=\mathrm{R}_{5}=\mathrm{H} ; \mathrm{R}_{3}=\mathrm{Glu}$

\section{Materials and Methods}

The ten flavonoid compounds were purchased from Shanghai Winherb Medical Technology Co., Ltd. (Shanghai, China) with a purity above $98 \%$. Leaves of four bamboo species, Pleioblastus amarus (Keng) Keng f., Phyllostachys glauca McClure, Phyllostachys edullis (Carrière)
J.Houz, and Indocalamus latifolius (Keng) McClure, were collected from Changning County, Sichuan Province, China in November, 2016 and identified by Guanghui Lai, Guangde Forestry and Grassland Bureau (Anhui, China). Vouchers registered as CDBI0152311 and CDBI0152265 for P. amarus and I. latifolius were deposited in the herbarium of Chengdu Institute of Biology, Chinese Academy of Sciences. Vouchers registered as SM720601535 and LBG00120870 for P. heterocycle and P. glauca were deposited in the Chongqing Academy of Chinese Materia Medica herbarium and the Lushan Botanical Garden, Chinese Academy of Sciences herbarium, respectively. Dried bamboo leaf powder $(10.0 \mathrm{~g})$ was macerated in a mixture $(100 \mathrm{ml})$ of ethanol $(\mathrm{EtOH}) / \mathrm{H}_{2} \mathrm{O}(3: 2)$ and treated with a sonicator $(250 \mathrm{~W}, \mathrm{KQ}-500$, Kunshan Ultrasonic Instrument Co., Ltd.) for $30 \mathrm{~min}$ at $50{ }^{\circ} \mathrm{C}$. After repeated extraction $(n=3)$, the extracted solution obtained by filtration was concentrated under reduced pressure and then diluted with water to $50 \mathrm{ml}$. The extract, after extraction with petroleum ether $(3 \times 150 \mathrm{ml})$, was evaporated to dryness with a rotary evaporator and subjected to a macroporous resin column (Diaion HP-20, Mitsubishi Chemical Corp., Tokyo, Japan) at a flow rate of $10 \mathrm{ml} / \mathrm{min}$ using $\mathrm{H}_{2} \mathrm{O} /$ EtOH (100:0, 85:15, 70:30, 50:50, 30:70, 5:95 v/v) as the solvent to produce six extracts. The solvent was removed under reduced pressure. The residue was reconstituted in $65 \% \mathrm{EtOH} / \mathrm{H}_{2} \mathrm{O}(10 \mathrm{ml})$, filtered through a $0.22-\mu \mathrm{m}$ cellulose membrane, transferred into glass vials, and stored at $-20{ }^{\circ} \mathrm{C}$ until analysis.

LC-MS-MS analysis was conducted by using a Bruker Advance UPLC system coupled with a Bruker EVOQ Elite triple quadrupole mass spectrometer (Bruker, Fremont, CA), which was connected to an electrospray ionization (ESI) source. The samples were injected onto an Agilent Eclipse XDB C-18 $(4.6 \times 150 \mathrm{~mm}, 5 \mu \mathrm{m})$ column. The flow rate was $0.8 \mathrm{ml} / \mathrm{min}$ with a split ratio of $1: 1$, and the column temperature was set at $40{ }^{\circ} \mathrm{C}$. Each sample was analyzed at least three times with an injection volume of $2 \mu \mathrm{l}$. The ESI source was operated in negative ion mode, and full scan mass spectral data were acquired over a range from mass-to-charge $(\mathrm{m} / \mathrm{z}) 50$ to 800 . Negative ESI mode was selected as the ionization mode for further optimization experiments. Multiple reaction monitoring (MRM) mode using the $m / z$ transitions of the precursor and product ions was applied to enhance sensitivity. The optimized mass spectrometric parameters were as follows: nebulizer gas flow, $60 \mathrm{ml} / \mathrm{min}$; probe gas flow, $50 \mathrm{ml} / \mathrm{min}$; cone temperature, $300{ }^{\circ} \mathrm{C}$; cone gas flow, $20 \mathrm{ml} / \mathrm{min}$; and probe temperature, $300{ }^{\circ} \mathrm{C}$.

To estimate the analytical parameters of the methodology for bamboo samples, intra-day precision, limits of detection and quantification, matrix effects, and recovery were evaluated. Five consecutive injections of each bamboo leaf 
extracts were performed on the same day to evaluate the method's precision. The results are expressed as relative standard deviations (RSDs). Calibration curves were established by injecting pooled standard solutions prepared from the standard mixtures. Calibration curves were constructed by plotting the concentrations of each target analyte versus the target analyte peak area using a linear regression analysis. A six-point calibration curve in the range of $0.1-50 \mu \mathrm{g} /$ $\mathrm{ml}$ was generated with correlation coefficients $\left(R^{2}\right)$ between 0.9955 and 0.9997 . The detection limits (LODs) and quantification limits (LOQs) were estimated at signal-to-noise $(\mathrm{S} / \mathrm{N})$ ratios of 3 and 10 , respectively. Recovery tests were carried out (five replicates) by spiking the compounds at three levels in the range of the calibration curves $(1,10$, and $50 \mu \mathrm{g} / \mathrm{ml}$, final concentration added) in the bamboo leaf samples before extraction, and a procedural blank was also carried out. Five replications of $10.0 \mathrm{~g}$ well-homogenized bamboo leaf composites were extracted and cleaned

a

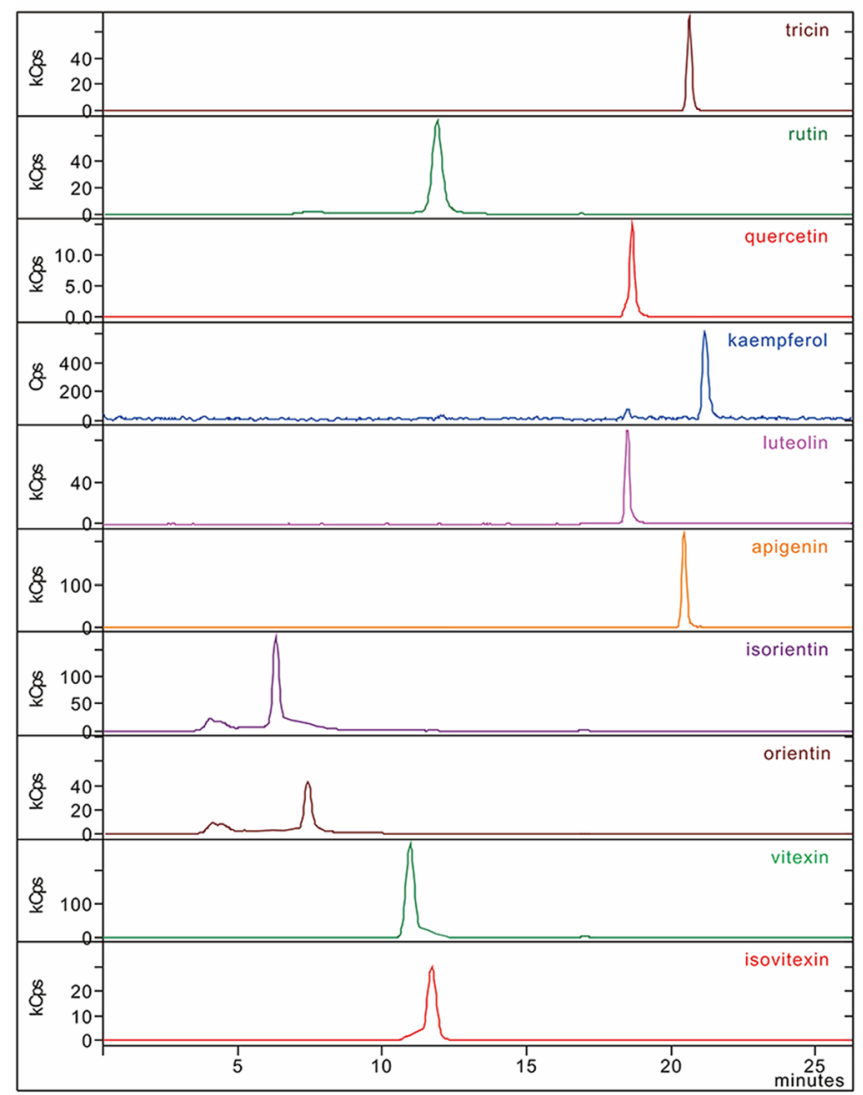

Retention Time(min)

Fig. 1 The extracted ion chromatograms of ten flavonoids. a Reference standards and $\mathbf{b}$ a mixture for one of the bamboo leaf extracts (Pleioblastus amarus). Kaempferol (1, Rt=21.18 $\mathrm{min})$, rutin (2, $\mathrm{Rt}=12.06 \mathrm{~min}) 0.85 \mu \mathrm{g} / \mathrm{ml}$; tricin $(3, \mathrm{Rt}=20.7 \mathrm{~min}) 0.0635 \mu \mathrm{g} / \mathrm{ml}$; orientin $(4, \mathrm{Rt}=7.25 \mathrm{~min}) 5.25 \mu \mathrm{g} / \mathrm{ml}$; quercetin $(\mathbf{5}, \mathrm{Rt}=19.07 \mathrm{~min})$ up with the procedures described above. The matrix effect was evaluated by comparing the slopes of the calibration curves obtained from the spiked bamboo leaf samples with the slopes of the calibration curves obtained from the standards. The signal of the analyte was considered enhanced if the quotient of the spiked sample curve slope and the standard curve slope was higher than 1 , whereas the signal of the analyte was considered suppressed if the value was lower than 1.

\section{Results and Discussion}

Individual target compound solutions were directly injected into the ESI-MS-MS system to identify the precursor and product ions under negative ionization modes. After choosing the precursor ions and product ions, the parameters for collision energy (CE) were

b

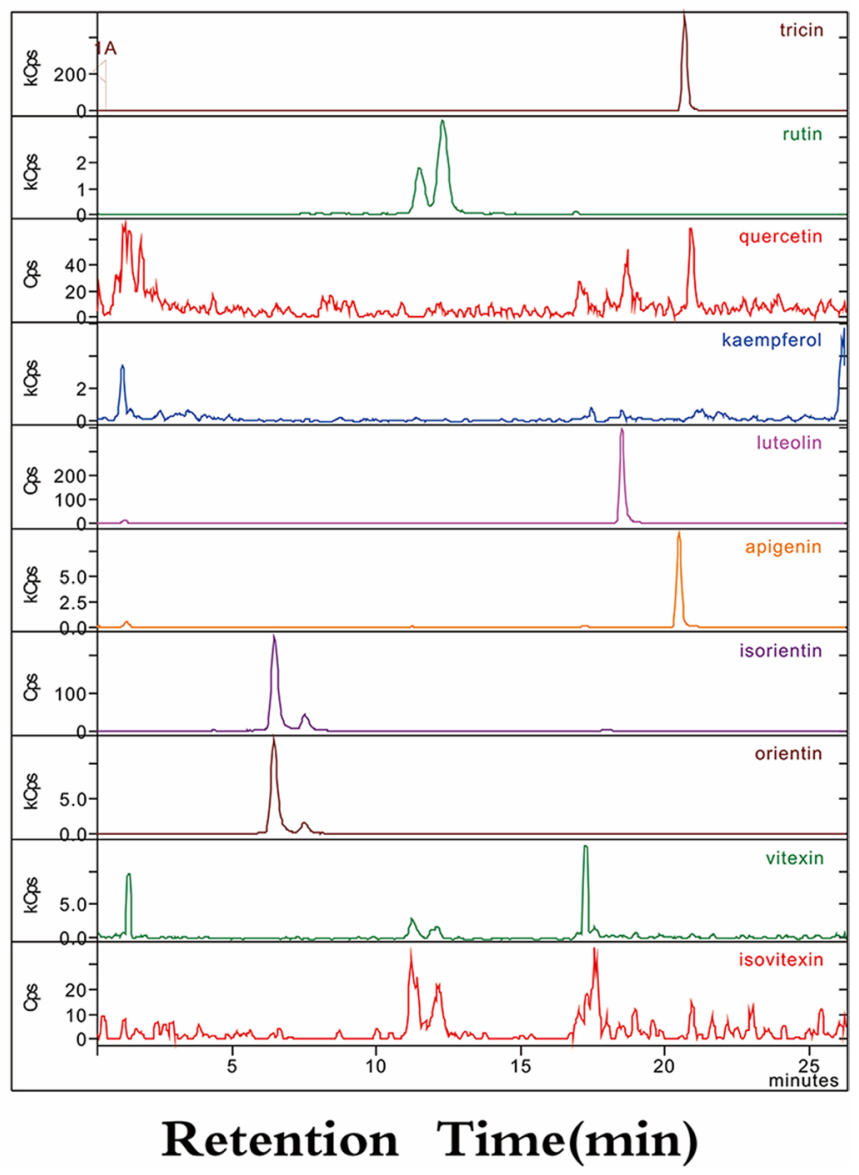

$0.35 \mu \mathrm{g} / \mathrm{ml}$; luteolin $(\mathbf{6}, \mathrm{Rt}=18.53 \mathrm{~min}) 0.13 \mu \mathrm{g} / \mathrm{ml} ; 0.0635 \mu \mathrm{g} /$ $\mathrm{ml}$; apigenin $(7, \mathrm{Rt}=20.97 \mathrm{~min}), 0.275 \mu \mathrm{g} / \mathrm{ml}$; isoorientin $(\mathbf{8}$, $\mathrm{Rt}=6.19 \mathrm{~min}) 1.5 \mu \mathrm{g} / \mathrm{ml}$; vitexin $(\mathbf{9}, \mathrm{Rt}=10.98 \mathrm{~min}) 2.5 \mu \mathrm{g} / \mathrm{ml}$; isovitexin $(\mathbf{1 0}, \mathrm{Rt}=11.71 \mathrm{~min}) 6.5 \mu \mathrm{g} / \mathrm{ml}$ 
Table 1 Intra-day precision, linearity, limits of detection (LOD), and limits of quantification (LOQ) of the analytes with LC-MS/MS

\begin{tabular}{llllll}
\hline Compound & Linearity & & LOQ $(\mathrm{ng} / \mathrm{ml})$ & LOD $(\mathrm{ng} / \mathrm{ml})$ & $\begin{array}{l}\text { Intra-day preci- } \\
\text { sion (RSD \%) }\end{array}$ \\
\cline { 2 - 3 } & Range $(\mu \mathrm{g} / \mathrm{ml})$ & $R^{2}$ & & & 1.12 \\
\hline Apigenin & $0.1-50$ & 0.9993 & 3 & 1 & 2.21 \\
Quercetin & $0.1-50$ & 0.9991 & 20 & 5 & 1.38 \\
Rutin & $0.1-50$ & 0.9985 & 100 & 30 & 3.12 \\
Luteolin & $0.1-50$ & 0.9971 & 5 & 2 & 2.34 \\
Kaempferol & $0.1-50$ & 0.9987 & 5 & 2 & 2.18 \\
Vitexin & $0.1-50$ & 0.9997 & 100 & 35 & 1.36 \\
Isovitexin & $0.1-50$ & 0.9993 & 150 & 45 & 3.26 \\
Orientin & $0.1-50$ & 0.9991 & 55 & 15 & 5.33 \\
Isoorientin & $0.1-50$ & 0.9978 & 90 & 25 & 3.45 \\
Tricin & $0.1-50$ & 0.9955 & 10 & 3 &
\end{tabular}

further optimized to obtain the maximum response of the precursor and product ions (Table S1). In this study, different mobile phases, such as methanol $(\mathrm{MeOH})$, acetonitrile $(\mathrm{MeCN})$, and a mixture of $\mathrm{MeOH}$ and $\mathrm{MeCN}$ $(50: 50, \mathrm{v} / \mathrm{v})$ with different compositions (ammonium acetate, formic acid at various concentrations), were tested. As expected, the addition of ammonium acetate into the mobile phases resulted in good peak shapes and enhanced the detection sensitivity for the majority of the target compounds. Finally, gradients consisting of $0.05 \%$ ammonium acetate in acetonitrile (mobile phase A) and $0.05 \%$ ammonium acetate in water (mobile phase B) were chosen as the appropriate mobile phases for routine LC-MS-MS analyses of the target compounds. The optimized gradient elution for LC separation was as follows: $0 \sim 15.00 \mathrm{~min}, 15 \% \mathrm{~A} ; 15.01 \sim 25.00 \mathrm{~min}, 35 \% \mathrm{~A}$; $25.00 \sim 27.00 \mathrm{~min}, 35 \% \mathrm{~A} \sim 100 \% \mathrm{~A} ; 27.00 \sim 28.00 \mathrm{~min}$, $100 \% \mathrm{~A} \sim 15 \% \mathrm{~A}$. The equilibration time before the next run was $6 \mathrm{~min}$. Under the described chromatographic conditions, all the compounds were eluted in a total run time of $25 \mathrm{~min}$. Figure 1 shows a chromatogram for all standard mixture after being optimized. Flavonoids were eluted in the order of isoorientin $(\mathbf{8}, \mathrm{Rt}=6.19 \mathrm{~min})$, orientin $(\mathbf{4}, \mathrm{Rt}=7.25 \mathrm{~min})$, vitexin $(\mathbf{9}, \mathrm{Rt}=10.98 \mathrm{~min})$, isovitexin $(\mathbf{1 0}, \mathrm{Rt}=11.71 \mathrm{~min})$, rutin $(2, \mathrm{Rt}=12.06 \mathrm{~min})$, luteolin $(\mathbf{6}, \mathrm{Rt}=18.53 \mathrm{~min})$, quercetin $(\mathbf{5}, \mathrm{Rt}=19.07 \mathrm{~min})$, tricin $(3, \mathrm{Rt}=20.7 \mathrm{~min})$, apigenin $(7, \mathrm{Rt}=20.97 \mathrm{~min})$, and kaempferol $(\mathbf{1}, \mathrm{Rt}=21.18 \mathrm{~min})$.

Analytical parameters, such as the linearity, precision of the method, and LOD, were calculated for the developed LC-ESI-MS-MS method. The intra-day RSD values ranged from 1.12 to $5.33 \%$ and were always $<10 \%$, indicating good intra-assay variation (Table 1). For the linearity study, calibration curves were determined for all the individual analytes in the six calibration standards $(0.1-50 \mu \mathrm{g} / \mathrm{ml})$ with correlation coefficients ranging between 0.9955 and 0.9997 (Table 1). The LOD and LOQ values for the target compounds ranged from 1 to $45 \mathrm{ng} / \mathrm{ml}$ and from 3 to $150 \mathrm{ng} /$ $\mathrm{ml}$, respectively (Table 1 ). The recoveries of the bamboo leaf flavonoids ranged from 68.45 to $112.31 \%$, with standard deviations ranging from 2.3 to $9.1 \%$ for the $0.1,0.2$, and $0.4 \mu \mathrm{g} / \mathrm{ml}$ spiking tests $(n=5$; Table $\mathrm{S} 2)$. The results of the
Fig. 2 Total flavonoids in different ethanol fractions of four bamboo leaf crude extracts

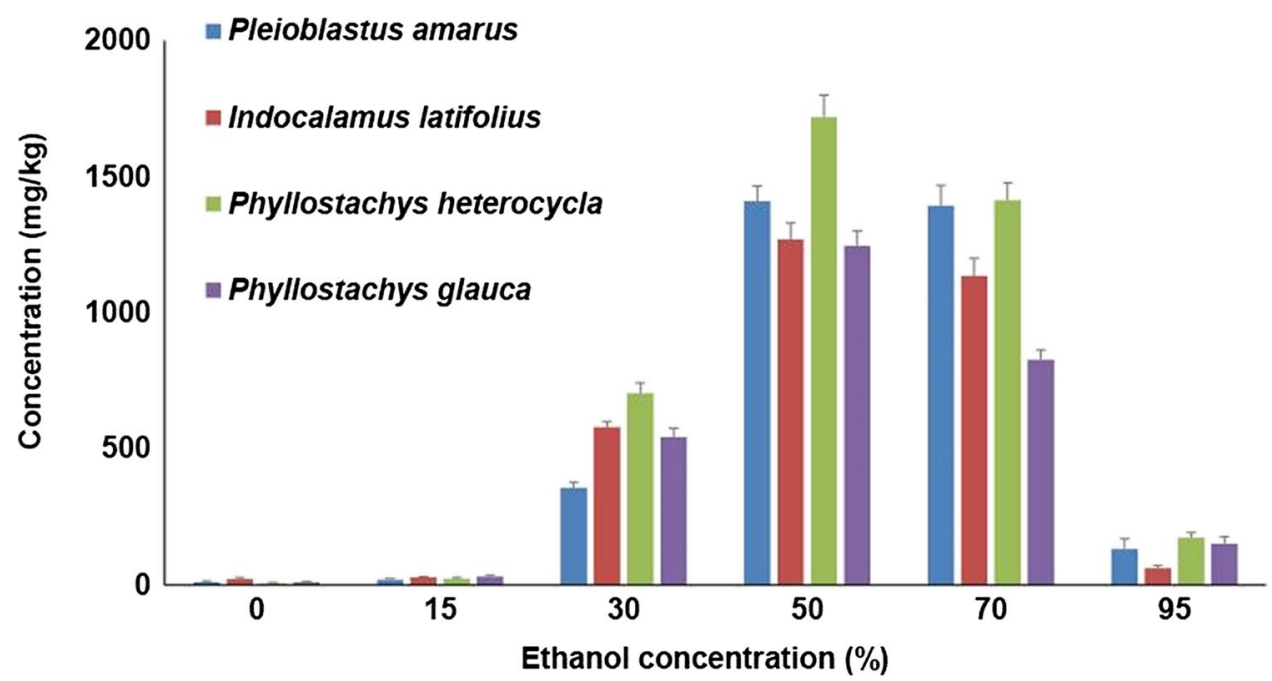


method validation revealed good sensitivity, precision, and accuracy for the simultaneous determination of all of the target compounds by the developed method.

The developed LC-MS-MS method was finally applied to the determination of ten major flavonoids from four bamboo leaf extracts ( $P$. amarus, I. latifolius, $P$. heterocycle, $P$. glauca) (Table S3) and the corresponding desorption solutions (EtOH concentration: 0, 15, 30, 50, 70, and 95\%, v/v) of the four bamboo leaf extracts (Table S4, 5, 6, 7). As summarized in Table S3, all four bamboo leaf extracts contained compounds 1-4, and the concentrations of these ten flavonoids were similar among the four species. Compounds $\mathbf{3}, \mathbf{4}$, and 9 were identified as major components in all the bamboo leaf extracts (Fig. S1), which is in agreement with previous studies (Jiao et al. 2007; Van Hoyweghen et al. 2012). The total concentrations of the flavonoids were 3321.09, $3095.96,4037.33$, and $2808.42 \mathrm{mg} / \mathrm{kg}$ in P. amarus, I. latifolius, $P$. heterocycle, $P$. glauca respectively (Table S3). The most abundant flavonoids that were determined in the four bamboo leaf extracts were $\mathbf{3}, \mathbf{2}$, and $\mathbf{4}$. It has been reported that these compounds are used as markers for the determination of bamboo leaf flavonoids in commercial products (Jiao et al. 2007; Zhang et al. 2005). Fig. S1 shows the compositions and contents of the ten flavonoids in different ethanol extracts of leaves from four species of bamboo. All the target analytes were detected in only the $30 \%$ and $50 \%$ EtOH extracts, and $\mathbf{2}$ and $\mathbf{4}$ were the dominant compounds in all of the examined samples. The highest content of total flavonoids was detected in the 50\% EtOH extract (Fig. 2) in all of the examined samples. This finding can also provide information for the further purification of flavonoid-rich extracts. The compositions and distributions of the detected flavonoids were similar in the leaf extracts from the four species of bamboo (Fig. 2). The information obtained in this study provides further support for the development of bamboo leaf extract as food supplements.

Supplementary Information The online version contains supplementary material available at https://doi.org/10.1007/s43450-021-00158-1.

Acknowlegements The helpful suggestions by the anonymous referees and editor-in-chief are gratefully acknowledged.

Author Contribution Data curation: LXB; experimental investigation, validation, and formal analysis: TWQ, XH, YX, WJ, and JS; funding acquisition: TF and YYD; supervision: TF; original draft preparation: LXB; writing, review and editing: $\mathrm{XH}$ and TF. All the authors have read and approved its submission.

Funding This work was supported by The Basic Science Research Fund Program of ICBR (No. 1632018007, 1632019022, 1632017005) and Yunnan Provincial Department of Education Science Research Fund Project (No. 2020J0764).
Data Availability Some or all data, models, or code that support the findings of this study are available from the corresponding author upon reasonable request.

\section{Declarations}

Conflict of Interest The authors declare no competing interests.

Open Access This article is licensed under a Creative Commons Attribution 4.0 International License, which permits use, sharing, adaptation, distribution and reproduction in any medium or format, as long as you give appropriate credit to the original author(s) and the source, provide a link to the Creative Commons licence, and indicate if changes were made. The images or other third party material in this article are included in the article's Creative Commons licence, unless indicated otherwise in a credit line to the material. If material is not included in the article's Creative Commons licence and your intended use is not permitted by statutory regulation or exceeds the permitted use, you will need to obtain permission directly from the copyright holder. To view a copy of this licence, visit http://creativecommons.org/licenses/by/4.0/.

\section{References}

An F, Yang G, Tian J, Wang S (2012) Antioxidant effects of the orientin and vitexin in Trollius chinensis Bunge in D-galactose-aged mice. Neural Regen Res 7:2565-2575. https://doi.org/10.3969/j. issn.1673-5374.2012.33.001

Gong J, Xia D, Huang J, Ge Q, Mao J, Liu S, Zhang Y (2015) Functional components of bamboo shavings and bamboo leaf extracts and their antioxidant activities in vitro. J Med Food 18:453-459. https://doi.org/10.1089/jmf.2014.3189

Hu C, Zhang Y, Kitts DD (2000) Evaluation of antioxidant and prooxidant activities of bamboo Phyllostachys nigra var. henonis leaf extract in vitro. J Agric Food Chem 48:3170-3176. https://doi. org/10.1021/jf0001637

Jian C, Yue Y, Feng T, Jin W (2011) HPTLC Analysis of the flavonoids in eight species of Indocalamus leaves. JPC-J Planar Chromat 24:394-399. https://doi.org/10.1556/JPC.24.2011.5.6

Jiao J, Zhang Y, Liu C, Liu J, Wu X, Zhang Y (2007) Separation and purification of tricin from an antioxidant product derived from bamboo leaves. J Agric Food Chem 55:10086-92. https://doi.org/ $10.1021 / \mathrm{jf} 0716533$

Koide CL, Collier AC, Berry MJ, Panee J (2011) The effect of bamboo extract on hepatic biotransforming enzymes-findings from an obese-diabetic mouse model. J Ethnopharmacol 133:37-45. https://doi.org/10.1016/j.jep.2010.08.062

Lee HJ, Kim KA, Kang KD, Lee EH, Kim CY, Um BH, Jung SH (2010) The compound isolated from the leaves of Phyllostachys nigra protects oxidative stress-induced retinal ganglion cells death. Food Chem Toxicol 48:1721-1727

Lu B, Wu X, Tie X, Zhang Y, Zhang Y (2005) Toxicology and safety of anti-oxidant of bamboo leaves. Part 1: acute and subchronic toxicity studies on anti-oxidant of bamboo leaves. Food Chem Toxicol 43:783-792. https://doi.org/10.1016/j.fct.2005.01.019

Ma X, Yan R, Yu S, Lu Y, Li Z, Lu H (2012) Enzymatic acylation of isoorientin and isovitexin from bamboo-leaf extracts with fatty acids and antiradical activity of the acylated derivatives. J Agr Food Chem 60:10844-10849. https://doi.org/10.1021/jf303595e

Mao JW, Yin J, Ge Q, Jiang ZL, Gong JY (2013) In vitro antioxidant activities of polysaccharides extracted from Moso Bamboo-Leaf. Int J Biol Macromol 55:1-5. https://doi.org/10.1016/j.ijbiomac. 2012.12.027 
Pereira CAM, Yariwake JH, McCullagh M (2010) Distinction of the $C$-glycosylflavone isomer pairs orientin/isoorientin and vitexin/ isovitexin using HPLC-MS exact mass measurement and insource CID. Phytochem Anal 16:295-301. https://doi.org/10. 1002/pca. 820

Sun J, Yue Y, Tang F, Guo X (2010) Simultaneous HPTLC analysis of flavonoids in the leaves of three different species of bamboo. JPC-J Planar Chromat 23:40-45. https://doi.org/10.1556/JPC.23. 2010.1.7

Van Hoyweghen L, De Beer T, Deforce D, Heyerick A (2012) Phenolic compounds and anti-oxidant capacity of twelve morphologically heterogeneous bamboo species. Phytochem Anal 23:433-443. https://doi.org/10.1002/pca.1377

Wang J, Tang F, Yue Y, Guo X, Yao X (2010) Development and validation of an HPTLC method for simultaneous quantitation of isoorientin, isovitexin, orientin, and vitexin in bamboo-leaf flavonoids. J AOAC Int 93:1376-1383. https://doi.org/10.1007/ s00003-010-0634-7

Wang J, Yue YD, Jiang H, Tang F (2012) Rapid screening for flavone $C$-glycosides in the leaves of different species of bamboo and simultaneous quantitation of four marker compounds by HPLCUV/DAD. Int J Anal Chem 205101:1-8. https://doi.org/10.1155/ 2012/205101
Wu D, Chen J, Lu B, Xiong L, He Y, Zhang Y (2012) Application of near infrared spectroscopy for the rapid determination of antioxidant activity of bamboo leaf extract. Food Chem 135:2147-2156. https://doi.org/10.1016/j.foodchem.2012.07.011

Yang JH, Choi MH, Yang SH, Cho SS, Park SJ, Shin HJ, Ki SH (2017) Potent anti-inflammatory and antiadipogenic properties of bamboo (Sasa coreana Nakai) leaves extract and its major constituent flavonoids. J Agric Food Chem 65:6665-6673. https://doi.org/10. 1021/acs.jafc.7b02203

Zhang Y, Bao B, Lu B, Ren Y, Tie X, Zhang Y (2005) Determination of flavone $C$-glucosides in antioxidant of bamboo leaves (AOB) fortified foods by reversed-phase high-performance liquid chromatography with ultraviolet diode array detection. J Chromatogr A 1065:177-185. https://doi.org/10.1016/j.chroma.2004.12.086

Zhang Y, Chen J, Zhang X, Wu X, Zhang Y (2007) Addition of antioxidant of bamboo leaves (AOB) effectively reduces acrylamide formation in potato crisps and French fries. J Agric Food Chem 55:523-528. https://doi.org/10.1021/jf062568i

Zu Y, Li C, Fu Y, Zhao C (2006) Simultaneous determination of catechin, rutin, quercetin kaempferol and isorhamnetin in the extract of sea buckthorn (Hippophae rhamnoides L.) leaves by RP-HPLC with DAD. J Pharm Biomed Anal 41:714-719. https://doi.org/10. 1016/j.jpba.2005.04.052 